\title{
RESPONSABILIDADE SOCIAL E SUSTENTABILIDADE NA EDUCAÇÃO SUPERIOR: PRODUÇÕES NA CAPES, ANPED E GUNI
}

\author{
SOCIAL RESPONSIBILITY AND SUSTAINABILITY IN HIGHER \\ EDUCATION: SCIENTIFIC PRODUCTIONS IN CAPES, ANPED and GUNI.
}

\author{
Ines Amaro da Silva ${ }^{1}$
}

\begin{abstract}
RESUMO
Os novos paradigmas científicos e as mudanças sociais desafiam as organizações a revisar seu modelo de desenvolvimento. Na Educação Superior, entidades internacionais apontam a educação para o desenvolvimento sustentável e a responsabilidade social da universidade como estratégias para repensar os sentidos do conhecimento, da investigação e da formação profissional, tendo em vista a mudança de mentalidades e a formação de uma cultura evolutiva, ecológica e socialmente consciente (MORIN, 2003). Nesse contexto, a abordagem complexa requer o desafio de integrar as dimensões dos impactos e dos princípios e processos noensino, na pesquisa, na extensão e na gestão universitária, tendo em vista a Responsabilidade Social e a Educação para o Desenvolvimento Sustentável. O artigo apresenta os resultados da pesquisa exploratória bibliográfica das produções científicas sobre estes temas nas Reuniões Anuais da ANPED, no banco de teses e dissertações da CAPES e no site do GUNI (Global University Network for Innovation), em 2009 e 2010. As produções encontradas exploram as contribuições da instituição de ensino para o desenvolvimento social, o estudo dos currículos na ótica da formação acadêmica para a responsabilidade social e as abordagens ligadas à gestão, embora poucas destas estejam voltadas a modelos de gestão integradores da responsabilidade social e da sustentabilidade. Para superar uma visão reducionista, é preciso aprofundar a compreensão crítica sobre a responsabilidade social e a sustentabilidade e a promoção de uma nova cultura de desenvolvimento, como possibilidades de repensar o papel das Universidades, alinhado com as exigências dos novos tempos.
\end{abstract}

Palavras-Chave: Responsabilidade Social. Sustentabilidade. Gestão Sustentável. Educação Superior.

\begin{abstract}
New scientific paradigm and social changes challenge organizations to give a new face to its development pattern. In Higher Education, international entities point to the education to sustainable development and the university social responsibility to rethink the knowledge meanings, the investigation and professional training , keeping in sight mentality changes and an evolutive culture formation as well as ecological and socially awareness(MORIN, 2003). In this context, the complex approach calls for integrate the dimensions of the impacts and of the principles and teaching processes, in the research, extension and university management being relevant to know the knowledge sate over Social Responsibility and Education to Sustainable Development and higher education to promote new breakthrough in this field. The article presents the outcome of bibliographic exploratory research of the scientific productions about this issue on ANPED Annual Meetings, at panel of thesis and treatise of CAPES and on GUNI (Global University Network for Innovation) site in 2009 and 2010.The productions found, explore the teaching institutions contributions to the social development, the curriculum study in the ambit of academic qualification to the social responsibility and the approach related to administration, yet few related to administrative patterns of social responsibility and sustainability. To overcome a reducionist view, it is essential to deepen the critical comprehensions about social responsibility and sustainability in promotion of a new development culture as possibilities for reconsider the role of universities in line with the demands of the new times.
\end{abstract}

Keywords: Social Responsibility. Sustainability. Sustainable Management. Higher Education.

\footnotetext{
1 Professora da Faculdade de Serviço Social da PUC- RS. Coordenadora de Desenvolvimento Social- PROEX PUCRS. Doutoranda em Educação. Email: ines.amaro@pucrs.br
} 


\section{INTRODUÇÃO}

As mudanças na primeira década do novo século, impulsionadas pelo avanço científico e tecnológico na sociedade do conhecimento e da informação, no contexto dos novos paradigmas e das tensões entre modernidade e pós-modernidade (MORIN,2005 e SANTOS, 2007), desafiam as organizações a repensar sua legitimidade social e rever as bases onde até então sustentaram seu desenvolvimento e mesmo, sua razão de ser.

A preocupação ética na perspectiva da solidariedade diacrônica com as gerações futuras e a ética imperativa da solidariedade sincrônica com a geração atual (SACHS, 2008), coloca o desenvolvimento sustentável e a responsabilidade social na agenda de organizações que, movidas por diferentes pressões e motivações, e em diferentes instâncias, questionam e buscam inovar ou transformar as formas excludentes, desiguais e fragmentadas que historicamente permeiam as relações entre os homens e com a natureza.

Pereira (2010) sintetiza a culminância de características muito particulares na virada de século, entre elas o avanço do neoliberalismo e a proliferação de discursos que ecoam em todos os cantos do planeta, como a sustentabilidade, a cidadania e a responsabilidade social, sinalizando algumas contradições da nova forma de sociabilidade, por exemplo, a coexistência entre políticas de inclusão e práticas de exclusão, ou mesmo a ilusão de progresso e de acesso, ao lado da violência contra os direitos humanos e sociais.

Como expressões do mundo contemporâneo, esses movimentos vêm sendo objeto de pesquisa e se gestam no campo científico no ambiente da crise das ciências. Diferentes paradigmas e epistemologias abalaram as estruturas da racionalidade cartesiana moderna e propõe novas formas de conhecer, saber e se relacionar, disputando lugar com diferentes "verdades" à cerca da vida e do aprender. Uma nova racionalidade, uma nova ciência, reconhecida como social e política e que produz interpretações sobre a realidade, e não mais uma verdade única e absoluta (STENGERS, 2002), passa se construir.

No contexto da educação superior, um conjunto de iniciativas internacionais lideradas por organizações como a OCDE e a UNESCO, aponta para a construção do conceito de qualidade, na perspectiva da educação para o desenvolvimento sustentável (MOROSINI, 2009). Estas entidades colocam na agenda das Instituições de Ensino Superior (IES) os novos paradigmas no processo de ensinar-aprender, o papel do conhecimento como fundamento do desenvolvimento sustentável da sociedade e as contribuições do ensino superior para a democracia e para a superação das grandes questões sociais e ambientais, na perspectiva da 
responsabilidade social e da sustentabilidade, destacando valores como acesso, igualdade, pertinência e relevância social. Referência fundamental para o tema encontra-se também na Década das Nações Unidas da Educação para o Desenvolvimento Sustentável 2005-2014, da UNESCO.

Considerando a tarefa prioritária da educação superior na crise civilizatória a necessidade de construção de novos paradigmas para uma sociedade planetária sustentável, compete as IES revisarem suas missões para equilibrar o conhecimento economicamente pertinente como conhecimento humano e social pertinente (SEGRERA, 2010). Por outro lado, percebemos que o compromisso social das IES e a defesa de ideais humanísticos na construção de uma sociedade justa e democrática, em especial no caso das universidades comunitárias, encontram pontos de convergência com relação ao seu papel no âmbito da responsabilidade social, assim como provocam a reflexão sobre as formas históricas de realização desse compromisso, exigindo atualização e inovação.

Assim, seja na dimensão do ensino, da pesquisa, da extensão e da gestão das IES, estes temas são ainda lugar de inquietação e desafiam a novas descobertas. No que se refere ao arcabouço legal, são relevantes as mudanças a partir da criação do Sistema Nacional de Avaliação da Educação Superior - SINAES, o qual inclui entre os seus objetivos e dimensões a responsabilidade social das IES, respeitando a identidade institucional e a autonomia. Entretanto, conforme constatado entre instituições do Consórcio das Universidades Comunitárias Gaúchas (COMUNG), a falta de precisão conceitual sobre temas como compromisso social, responsabilidade social e assistência social, ficou evidenciada na análise prévia de documentos e de projetos institucionais dessas instituições (OLIVEIRA et all, 2009). Soma-se a isso o conceito de sustentabilidade que, ao evocar uma "ética da perpetuação da humanidade e da vida" (VEIGA, 2008, p. 165), não é uma noção precisa, analítica, passível de ser encontrada em estado puro. Por si só, a sustentabilidade é contraditória e diz respeito a outro modelo de desenvolvimento, o desenvolvimento sustentável.

No exercício profissional como docente e gestora, observo um conjunto de ações e iniciativas cotidianas nas universidades voltadas a aprofundar o debate, revisar, sistematizar, consolidar e/ou modificar políticas e práticas, bem como criar e inovar, de forma transversal, nos âmbitos do ensino, da pesquisa, da extensão e da administração. Um profícuo processo de construção e implantação de modelos de gestão da responsabilidade social e educação sustentáveis concorre com a imprecisão conceitual vigente, o tempo histórico recente e as mudanças institucionais que a responsabilidade social e a educação para o desenvolvimento 
sustentável na Educação Superior solicitam, provocando resistências e o risco de uma apreensão reducionista, pragmática e/ou parcial das demandas, implicando em iniciativas dispersas ou mesmo isoladas dentro das universidades.

Assim, responsabilidade social e a sustentabilidade, como categorias que expressam uma síntese de complexas e contraditórias variáveis e determinações do capitalismo mundial, convidam a universidade à reflexão crítica, à discussão interna, ao alinhamento de concepções e ao desenvolvimento de um modelo de gestão sustentável coerente com a identidade, a cultura e o posicionamento institucional de cada IES. Como a produção científica tem capturado, analisado, revelado esse movimento da responsabilidade social, da sustentabilidade, da gestão e educação na Educação Superior, no âmbito do ensino, da pesquisa, da extensão e da gestão institucional?

Com o propósito de identificar o estado do conhecimento sobre a Responsabilidade Social e a Sustentabilidade na Educação Superior, com vistas a orientar futuras pesquisas, realizei um levantamento das produções científicas nos anos de 2009 e 2010 sobre este tema, na ANPED, na CAPES e no site do GUNI (Global University Network for Innovation), este último por ser uma referência internacional na publicação de artigos e promoção de eventos científicos sobre este assunto. A metodologia utilizada envolveu a identificação e seleção das fontes, buscas por palavras-chave e leitura flutuante do material encontrado. O presente artigo apresenta o caminho e os resultados encontrados nesse percurso, bem como expõe lacunas e explora possibilidades para aprofundar o processo de conhecimento e compreensão crítica deste movimento no real, com vistas a oferecer subsídios para impulsionar e incrementar processos de mudança e de transformação em direção ao aprimoramento das relações universidade e sociedade, na ótica da responsabilidade social e da sustentabilidade. Considerando que uma pesquisa exploratória bibliográfica mais detalhada foi feita nas teses, dissertações e artigos com assuntos e abordagens mais diretamente relacionadas ao tema objeto deste estudo, os achados poderão ainda subsidiar novas artigos acadêmicos, focalizadas de forma mais específica na análise dos conteúdos dessas produções.

\section{Delimitações conceituais}

Considerando que qualquer mudança pedagógica deve ser contextualizada na reflexão sobre as relações educação-sociedade (BERTRAND, 2001), o paradigma emergente na sociedade do século XXI traduz-se em tendências e teorias pedagógicas contemporâneas que convergem e dialogam com riqueza de possibilidades para uma educação alinhada com a 
responsabilidade social e o desenvolvimento sustentável. Responsabilidade social da universidade (RSU) e educação para o desenvolvimento sustentável (EDS) não se reduzem à adaptação às demandas e urgências do mundo econômico, ao contrário, implicam repensar os sentidos de ciência e tecnologia e, portanto, de investigação e de formação profissional, com base em princípios de co-responsabilidade, justiça e eqüidade (GOERGEN,2008). Assim, a educação como um sistema aberto (MORAES, 2005) é uma das principais forças de transformação para a mudança de mentalidades e formação de uma cultura evolutiva consciente, ecológica e socialmente (MORIN, 2003).

No contexto desse artigo, a responsabilidade social e o desenvolvimento sustentável nas universidades são entendidos a partir do referencial proposto por autores que abordam o tema em duas dimensões, os impactos e os princípios e processos, ambas sustentadas em um enfoque que inclui os quatro grandes sistemas das universidades: ensino, pesquisa, extensão e gestão. Entre os autores, Vallaeys (2006) define a responsabilidade social das universidades como uma política de qualidade ética nas atividades da comunidade universitária, através de uma gestão responsável dos serviços educativos, cognitivos, laborais, sociais e ambientais, em um diálogo participativo com a sociedade, para promover o desenvolvimento humano sustentável. Na mesma perspectiva, Zaffaroni (2007) distingue cinco áreas de impacto que as universidades têm: organizacional, ambiental, educacional, cognitivo e social.

Caminhar em direção a um modelo de desenvolvimento sustentável requer o avanço da ciência, investimento em pesquisa e desenvolvimento de tecnologias inovadoras, bem como estratégias de planejamento e gestão pautadas em lógicas antes impensadas, já que a questão do uso dos recursos naturais parecia ilimitada e a pobreza e as desigualdades sociais, para muitos, seriam solucionadas pelo crescimento econômico. Requer, também, desencadear processos de formação, seja em espaços de educação formal, seja em espaços informais, para o desenvolvimento dessa nova consciência e de valores e competências (conhecimentos, habilidades e atitudes) que produzam novos sentidos, necessidades e aspirações que vão tecendo uma rede social e cultural em micro e macro escala a qual, ao mesmo tempo em que constitui vai sendo constantemente alimentada no processo de produção dessa sustentabilidade da vida e do desenvolvimento.

A par das conceituações acima, observa-se que na realidade das universidades persistem equívocos e imprecisões na leitura e compreensão dos significados dessas novas demandas. Calderon (2006) aponta para a fragilidade de entendimento do conceito da responsabilidade social universitária nas IES e os desafios de sua implantação como modelo de gestão de ética 
e transparência. A RSU e a EDS não pode ser confundida com a mera execução de projetos sócio-ambientais nas comunidades, nem com meras estratégias apelativas de marketing ou maquiagem social preparada para os avaliadores.

A visão da GUNI sintetiza essa compreensão ao entender a responsabilidade social universitária como a capacidade que tem a universidade, como instituição, de difundir e colocar em prática um conjunto de princípios e valores, por meio de quatro processos principais: gestão, docência, investigação e extensão. Os princípios e valores abrangem os planos pessoal (dignidade da pessoa, liberdade e integridade), universitário (compromisso com a verdade, excelência, interdependência e transdisciplinaridade) e social, que contempla o bem comum e a equidade social, o desenvolvimento sustentável e meio ambiente, a sociabilidade e solidariedade para a convivência, a aceitação e apreço à diversidade e a cidadania, democracia e participação (MOROSINI, 2008).

A partir deste entendimento, busquei nesse artigo identificar tanto a produção atual disponível nos conceituados referenciais acadêmicos já mencionados, quanto identificar em que perspectivas e concepções essa produção sobre a Responsabilidade Social e a Sustentabilidade na Educação Superior está sendo abordada.

\section{Caminho metodológico e principais resultados}

As palavras-chave utilizadas para as buscas sobre dissertações, teses e artigos foram Responsabilidade Social, Sustentabilidade, Gestão Sustentável, Universidade Educação e/ou Ensino Superior.

Comecei a pesquisa pela Associação Nacional de Pós-Graduação e Pesquisa em Educação - ANPED. A ANPED tem como finalidade o desenvolvimento e a consolidação do ensino de pós-graduação e da pesquisa na área da Educação no Brasil e é uma entidade reconhecida que tem se projetado, no país e fora dele, como um importante fórum de debates das questões científicas e políticas da área da Educação, tendo se tornado referência para acompanhamento da produção brasileira no campo educacional ${ }^{2}$. A entidade mantém sempre atualizada a sua produção através das reuniões anuais, apresenta qualidade certificada pela CAPES- Qualis A e disponibiliza pela internet os artigos.

Inicialmente pesquisei as produções dos Grupos de Trabalho da 33a . Reunião Anual, ocorrida em 2010. Realizei uma leitura flutuante sobre os títulos de todos os trabalhos dos grupos, para ter uma noção dos assuntos mais trabalhados e suas possíveis relações com o

${ }^{2}$ http://www.anped.org.br/internas/ver/sobre-a-anped?m=1 consultas em 08/04/2011 e 15/04/2011 
tema de pesquisa. Após esta primeira aproximação, selecionei os grupos que apresentaram maior tendência de abordarem assuntos relacionados com o tema, pois não identifiquei nenhum título que abordasse especificamente Responsabilidade Social e Sustentabilidade na Educação Superior, o que me fez perceber neste momento a existência de ampla gama de subtemas afins. Foram consultados então os seguintes Grupos de Trabalho da ANPED: GT 05 - Estado e Política Educacional, GT 12 - Política de Educação Superior, GT 14 - Sociologia da Educação, GT 21 - Educação e Relações Etnico-Raciais, GT 23 - Gênero, Sexualidade e Educação e GT 22 - Educação Ambiental (na perspectiva de fundamentos teóricos e novos paradigmas).

Como não identifiquei diretamente a Responsabilidade Social e/ou Sustentabilidade na Educação Superior nas produções pesquisadas, também recorri aos dois anos anteriores - as $32^{\mathrm{a}}$. e 31 ${ }^{\mathrm{a}}$. Reuniões da ANPED, realizadas nos anos de 2009 e 2008, respectivamente. Igualmente não foram localizadas produções sobre o tema.

Num segundo momento, consultei o banco de dissertações e teses da CAPES, cujos títulos estivessem relacionados à Responsabilidade Social, Sustentabilidade e Gestão Sustentável na Universidade e Educação e/ou Ensino Superior. Comecei pelo ano de 2009, considerando que o ano de 2010 ainda não estava disponível e, na sequência, como fui encontrando produções a cada ano, coloquei como limite de pesquisa o ano 2000 (nova década) e, assim, pesquisei na Capes as produções dos anos de 2000 a $2009^{3}$

Por fim, consultei o site daGlobal University Network for Innovation - GUNI ${ }^{4}$, entidade que congrega 179 estabelecimentos de ensino superior e centros de inovação e de redes ligadas à inovação e compromisso social do ensino superior, com representação de 68 países, cuja missão é contribuir para o fortalecimento do papel do ensino superior na sociedade, através da renovação e da inovação e sob uma visão de serviço público, relevância e responsabilidade social.Pesquisei as produções disponibilizadas no site através de notícias e artigos, bem como materiais referentes à V Conferência de Barcelona de Educação Superior, cujo tema foi $O$ Compromisso do Ensino Superior para a Sustentabilidade: do Entendimento para a Ação, ocorrida em Barcelona, de 23 a 26 de novembro de $2010^{5}$.

Nos levantamentos realizados, identifiquei que a amplitude do tema estudado permite aproximações por diferentes caminhos e perspectivas. Tanto na CAPES quanto na GUNI encontrei produções (dissertações, teses e artigos) específicas sobre o tema, já no site da

\footnotetext{
${ }^{3}$ http://capesdw.capes.gov.br/capesdw/acessos em 11/5/2011 e 12/05/2011

4 http://www.guni-rmies.net/info/default.php?id=1; http://www.guni-rmies.net/news/default.php?sec=89 acessos em $20 / 11 / 2010$ e $14 / 5 / 2011$

${ }^{5}$ www.guninetwork.org/conference2010, acesso em 11/5/2011 e 12/05/2011
} 
ANPED constatei que o tema não tem sido abordado diretamente, mas sim através de um conjunto de tópicos que guardam relação de maior ou menos proximidade com o mesmo. Esta pré-análise permitiu mapear algumas questões que foram aparecendo de forma significativa e permitiram identificar e diferenciar, nas produções encontradas, as seguintes dimensões:

$\checkmark$ Paradigmas e Teorias da Educação: associado ao tema da Responsabilidade Social e Sustentabilidade na Educação, aparecem produções que tratam de teorias, tendências e práticas pedagógicas relacionadas aos paradigmas emergentes (denominado complexidade, holístico e/ou sistêmico), bem como sobre uma diversidade de novos temas decorrentes. Embora na sua maioria estas produções não mencionem o tema deste artigo, tratam de assuntos de alguma forma relacionados ao mesmo e que passamos a considerar como subtemas, por exemplo, a educação inclusiva e a educação ambiental e seus desdobramentos: educação para democracia e cidadania, educação para paz, diversidade, igualdade e equidade, espiritualidade e subjetividade, interdisciplinaridade. Em especial na ANPED se destacam estas produções, e na maioria das vezes não abordam a Educação Superior, a maior parte está voltada para o ensino fundamental e médio.

$\checkmark$ Dimensão Político-Institucional da Educação: identifiquei produções sobre a legislação brasileira e os Planos Nacionais de Educação (PNE) que apontam para a garantia do direito à educação de qualidade, à gestão democrática e à avaliação, bem como para a democratização do acesso, permanência e sucesso escolar, justiça social e inclusão social, indicando o compromisso com a equidade (justiça e inclusão), embora não tratem diretamente do tema da responsabilidade social e da educação para o desenvolvimento sustentável.

$\checkmark$ Responsabilidade Social e Sustentabilidade no Ensino Superior: as produções que tratam diretamente do tema o abordam em diferentes perspectivas e com diferentes compreensões, enfocando em geral um ou mais dos seguintes aspectos da responsabilidade social ou da sustentabilidade|: na gestão institucional, no ensino e na extensão.

Os artigos e as dissertações e/ou teses foram selecionados por aproximações com a temática e foram permitindo a classificação por categorias. Simultaneamente, fomos destacando os eixos principais de interesse, dentro de dois aspectos encontrados - por um lado a pouca produção específica sobre o assunto em algumas fontes, de outro a amplitude e a gama de possibilidades de abordagem do assunto em outras fontes. Assim, optei por apresentar os dados totais das pesquisas, num primeiro momento.

A tabela abaixo se refere às produções encontradas na ANPED. Apresenta o total de artigos por GT analisado, nas reuniões anuais de 2009 e 2010, bem como o número de artigos encontrados com subtemas relacionados ao tema da investigação. 
Tabela 1 - Responsabilidade Social e Sustentabilidade na ANPED - produção científica nos GTs selecionados, nas Reuniões Anuais de 2008, 2009 e 2010.

Reunião

Anual

2010

2009
Grupo de Trabalho (GT)

05- Estado e política educacional

11- Política de educação superior

21- Educação e relações étnico raciais

22- Educação ambiental

Subtotal

05- Estado e política educacional

11- Política de educação superior

21- Educação e relações étnico raciais

22- Educação ambiental

23- Gênero, sexualidade e educação

\section{Subtotal}

11- Política de educação superior

21- Educação e relações étnico raciais

22- Educação ambiental

23- Gênero, sexualidade e educação

Subtotal

\section{Total de Artigos com artigos subtemas/afin}

$\begin{array}{cc} & \mathbf{s} \\ 20 & 0 \\ 13 & 2 \\ 13 & 4 \\ 22 & 7 \\ \mathbf{6 8} & \mathbf{1 3} \\ 12 & 0 \\ 12 & 3 \\ 9 & 3 \\ 5 & 2 \\ 15 & 4 \\ \mathbf{5 3} & \mathbf{1 2} \\ 14 & 4 \\ 11 & 0 \\ 12 & 3 \\ 11 & 0 \\ \mathbf{5 4} & \mathbf{7} \\ 112 & 25\end{array}$

0

2

0

3

3

2

12

4

0

25

Total

Fonte: elaborada pela autora

$\mathrm{Na}$ análise de títulos e resumos, do total de 112 trabalhos, nenhum se refere especificamente à Responsabilidade Social e/ou Sustentabilidade na Educação Superior, nem em seu título, nem através dos resumos analisados. Entretanto, 25 artigos (22,3\%)abordam subtemas relacionados à responsabilidade social e/ou sustentabilidade, seja diretamente na educação superior ou sobre a formação docente e fundamentos teóricos relacionados ao assunto.

A tabela acima também nos permite verificar que há um aumento tanto na produção geral de artigos nos GTs analisados no ano de 2010, mas permanece uma mesma média de artigos com subtemas afins. Observo uma tendência a abordar os assuntos referentes à legislação e à política institucional com tópicos relacionados à responsabilidade socioambiental e compromisso social, bem como outras duas vertentes relacionadas ao assunto e que estão separadas em diferentes GTs, que são: inclusão social e educação ambiental. De qualquer forma, o tema deste artigo não tem sido tratado diretamente pelos GTs da ANPED. 
A Tabela 2, abaixo, destaca o total da produção de artigos com temas afins dos anos de 2009 e 2010. Agrupei os 25 artigos em três categorias, que expressam: questões conceituais e paradigmáticas mais amplas e fundamentos legais promotores de mudanças, as quais de alguma forma relacionam-se à responsabilidade social e sustentabilidade na educação e abordagens específicas para a educação superior, em bem menos quantidade; temas afins na área de educação ambiental e inclusão social, embora em sua maioria voltados ao ensino médio, de forma que selecionamos aqueles que tratam de formação docente e de questões teóricas que podem servir de subsídios para a educação em geral.

Tabela 2 -Responsabilidade Social e Sustentabilidade na ANPED - artigos com temas afins, por categorias,nas Reuniões Anuais de 2009 e 2010.

\begin{tabular}{|c|c|c|c|}
\hline Categoria & $\begin{array}{l}\mathbf{N} . \\
\text { artigos }\end{array}$ & $\%$ & Subtemas / temas afins \\
\hline Legislação & 5 & 20 & Reforma/Papel social da universidade \\
\hline e Política & & & Universidade socialmente referenciada/democrática \\
\hline Instituciona & & & Institucionalização da Educação Ambiental \\
\hline $1 \mathrm{na}$ & & & Acesso/Inclusão Social \\
\hline $\begin{array}{l}\text { Educação } \\
\text { Superior }\end{array}$ & & & Privatização e Publicização da Educação \\
\hline Educação & 9 & 36 & Redes socioambientais como ambiente educativo \\
\hline Ambiental & & & $\begin{array}{l}\text { Teoria da complexidade, teoria crítica, crise dos } \\
\text { paradigmas. } \\
\text { Educação, meio ambiente e cidadania - agenda } 21 \\
\text { Produção Científica em Educação Ambiental(EA) } \\
\text { Pedagogia Crítica e Formação Educadores em EA } \\
\text { Formação Docente }\end{array}$ \\
\hline Educação & 11 & 44 & Educar para relações étnico-raciais \\
\hline Inclusiva - & & & Ações afirmativas - povos indígenas e relações raciais \\
\hline Inclusão & & & Produção científica ANPED sobre relações de gênero e \\
\hline Social e & & & sexualidade \\
\hline $\begin{array}{l}\text { Diversidad } \\
\text { e }\end{array}$ & & & $\begin{array}{l}\text { Produção científica ANPED sobre afro brasileiros, } \\
\text { identidade e diferença }\end{array}$ \\
\hline & & & Heteronormatividadeee homofobia na educação \\
\hline & & & Docência, homossexualidade e travestilidade \\
\hline & & & Professores Universitários e identidade racial \\
\hline
\end{tabular}

Total $25 \quad 100$

Fonte: elaborado pela autora

O passo seguinte foi a realização de pesquisa no banco de teses e dissertações da CAPES, onde identifiquei um quadro bem diferente. Em um primeiro momento, apresento na Tabela 3 apresento o total de produções encontradas na busca geral realizada no período de 2000 a 2009.

Tabela 3 - Responsabilidade Social, Sustentabilidade e Gestão Sustentável na 
Educação Superior- Teses e Dissertações na CAPES no período de 2000 a 2009.

Palavras-Chave

Responsabilidade Social e Educação

Superior

Responsabilidade Social e Ensino

Superior

Responsabilidade Social Universitária

Sustentabilidade e Educação Superior

Sustentabilidade e Ensino Superior

Sustentabilidade e Universidade

Gestão Sustentável e Educação Superior

Gestão Sustentável e Ensino Superior

Gestão Sustentável e Universidade
2000-2003

25

20

$5 \quad 8$

$5 \quad 19$

420

68

3

5

36
Anos

Total

2000-2009

109

$48 \quad 59$

40

181

Fonte: elaborado pela autora

A tabela acima apresenta o total de teses e dissertações que aparece em cada grupo de palavras-chave, independente de repetições e de serem ou não produções especificamente voltadas ao campo da educação superior, embora estejam assim catalogadas. Embora se encontrem produções desde o ano 2000, observei um significativo incremento nas produções a partir do ano de 2004, e, na palavra-chave Responsabilidade Social e Sustentabilidade, outro incremento a partir dos anos 2007.

A Tabela 4 apresenta as produções na CAPES em 2009, pelas palavras-chave pesquisadas. Ainda que eu tenha utilizado junto aos termos Responsabilidade Social, Sustentabilidade e Gestão Sustentável, às expressões Universidade, Educação e/ou Ensino Superior, identifiquei que muitas produções eram relacionadas à Responsabilidade Social e Sustentabilidade em outros espaços organizacionais, ainda que a partir de trabalhos eventualmente desenvolvidos por Universidades. Tal constatação afastava tais produções do objeto deste estudo.

Por este motivo, a tabela abaixo apresenta o total de produções encontradas em cada grupo de palavras-chave e, destas, as produções específicas no tema deste estudo. Dessa forma, no ano de 2009, ano mais recente que está disponível no site da CAPES, encontrei 30 produções específicas na área de Responsabilidade Social, Sustentabilidade e Gestão Sustentável na Educação Superior. Importante observar que as classificações por assunto no site, os variados resultados encontrados, os títulos dos documentos e os resumos revelam e 
corroboram as diferentes concepções, abordagens e formas de tratar este tema, conforme apontado na introdução deste estudo.

Importante também comentar que, como constatei que utilizando as expressões Universidade, Educação e/ou Ensino Superior e Gestão Sustentável, apareciam algumas produções novas, optei por trabalhar com este conjunto de palavras-chave agrupadas. Por outro lado, como são grupos de palavras-chave semelhantes, a observação mais detalhada das produções do ano de 2009 permitiu constatar a ocorrência de algumas repetições, as quais foram assinaladas de forma que mantive apenas sua contagem por uma vez, na primeira vez que apareceram, eliminando sua ocorrência nas vezes seguinte.

Por este motivo, na Gestão Sustentável, última pesquisada, ainda que de fato apareçam em bem menor quantidade produções específicas na educação superior, apareceram também teses e dissertações repetidas, de forma que destaquei apenas aquela que ainda não havia sido computada, mantendo o mesmo procedimento.

\begin{tabular}{|c|c|c|c|}
\hline \multicolumn{4}{|c|}{$\begin{array}{c}\text { Tabela } 4 \text { - Responsabilidade Social e Sustentabilidade na Educação Superior- Tese } \\
\text { e Dissertações na CAPES no ano de } 2009\end{array}$} \\
\hline \multirow[t]{2}{*}{ Palavras-Chave } & \multicolumn{3}{|c|}{ Frequência } \\
\hline & $\begin{array}{l}\text { Produção } \\
\text { Total }\end{array}$ & $\begin{array}{l}\text { Produção } \\
\text { Específica }\end{array}$ & Percentual \\
\hline Responsabilidade Social e Educação & 21 & 6 & $25,9 \%$ \\
\hline Superior* & & & \\
\hline Responsabilidade Social e Ensino Superior* & 26 & 6 & \\
\hline Responsabilidade Social Universitária* & 11 & 3 & \\
\hline Subtotal Responsabilidade Social & 58 & 15 & \\
\hline Sustentabilidade e Universidade & 65 & 9 & $15,4 \%$ \\
\hline Sustentabilidade e Ensino Superior* & 14 & 0 & \\
\hline Sustentabilidade e Educação Superior* & 12 & 5 & \\
\hline Subtotal Sustentabilidade & 91 & 14 & \\
\hline Gestão Sustentável e Ensino Superior* & 10 & 1 & $2,3 \%$ \\
\hline Gestão Sustentável e Educação Superior* & 9 & 0 & \\
\hline Gestão Sustentável e Universidade* & 26 & 0 & \\
\hline Subtotal Gestão Sustentável & 44 & 1 & \\
\hline TOTAL & 193 & 30 & $15,5 \%$ \\
\hline
\end{tabular}

Fonte: elaborado pela autora

Não foi interesse deste estudo identificar outras informações, por exemplo, diferenciar as teses das dissertações, identificar a produção por Estado e/ou por tipo de instituição de ensino, entre outras possíveis variáveis. Meu interesse foi mapear a quantidade de produções no tema, bem como classificar as perspectivas em que o mesmo vem sendo proferencialmente 
abordado. Neste sentido, a análise das produções (títulos e resumos), permitiu criar um novo esquema de classificação, com a utilização de novas categorias. A Tabela 5 apresenta estas produções, classificadas pelas categorias de Ensino, Extensão, Ensino-Extensão eGestão na área da Responsabilidade Social e da Sustentabilidade na Educação Superior.

Tabela 5 - Teses e Dissertações na CAPES em 2009, por palavra-chave e categorias Categoria Frequência

Responsabilidade Social na Extensão

\section{Fonte: elaborado pela autora}

No que se refere à responsabilidade social, 8 teses e dissertações $(27,6 \%)$ tratam do tema na dimensão no ensino e/ou na extensão, referindo-se em especial a perspectiva das contribuições da instituição de ensino para a sociedade e/ou para o desenvolvimento das comunidades do entorno através de programas e projetos de extensão e a perspectiva dos currículos de alguns cursos, estudados na ótica da formação acadêmica para a responsabilidade social e das contribuições do curso para as comunidades. Em relação à responsabilidade social na dimensão da gestão institucional, encontrei 7 teses e dissertações,. Somam-se as produções sobre gestão sustentável e temos mais 10 produções, ou seja, um total de 17 teses e dissertações sobre a Gestão $(58,6 \%)$, explorando diferentes perspectivas: inclusão social dos alunos, gestão de stakeholders, indicadores de gestão sustentável, 
competências do gestor, diretrizes para uma gestão sustentável, entre outras. A dimensão ambiental, seja no âmbito da gestão ou da educação ambiental, tratei separadamente e corresponde a 13,8\% (4 teses e dissertações).

Por fim, verifiquei o site da GUNI, onde localizei a postagem de artigos sobre o tema a partir do ano de 2010, até maio de 2011. Os artigos encontrados situam-se nas seguintes categorias/abordagens, conforme apresentado na Tabela 6, abaixo.

Tabela 6 - Responsabilidade Social e Sustentabilidade na Educação Superior Artigos no site do GUNI nos anos 2010 e 2011

Categorias

Frequência

Extensão

Ensino

Gestão

Total

Fonte: elaborado pela autora

Nas produções da GUNI destacam-se igualmente artigos voltados à responsabilidade social e sustentabilidade na perspectiva da extensão (40\%), sob a ótica do compromisso cívico com as comunidades e o desenvolvimento social; do ensino (15\%), na ótica do impacto acadêmico e de princípios educativos na formação; da gestão (45\%), onde se inserem um conjunto de abordagens que exploram fundamentos teóricos e concepções sobre a sustentabilidade, valores e diretrizes e indicadores de gestão. 
A figura abaixo sintetiza as produções da CAPES e da GUNI nas categorias da Responsabilidade Social e Sustentabilidade no Ensino, na Extensão e na Gestão das IES. Do total de 49 trabalhos, mais da metade estão no campo da gestão. Não encontramos produções que abordem a dimensão das contribuições ou papel da pesquisa em relação a estes temas.

Figura 1 - Total absolto e percentual das produções da CAPES (2009) e da GUNI (2010 e até abril de 2011) nas categorias da Responsabilidade Social e da Sustentabilidade na Educação Superior no Ensino, na Extensão e na Gestão.

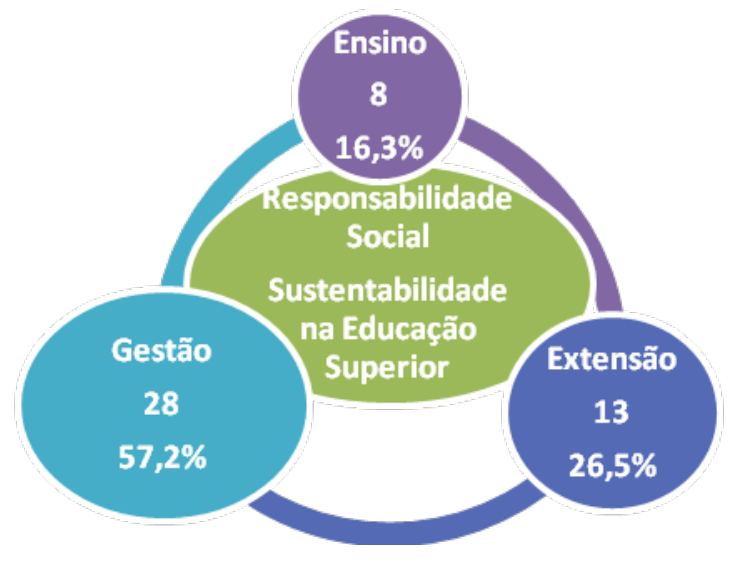

Fonte: Elaborado pela autora

Da análise das produções da ANPED, da CAPES e da GUNI e tendo como ponto de partida as dimensões destacadas no início deste item, ao final deste percurso identifiquei que a temática da Responsabilidade Social e da Sustentabilidade na Educação Superior vem sendo abordada nos seguintes grandes eixos/categorias:

- Legislação e Políticas Institucionais

- Gestão Institucional

- Formação, no âmbito do Ensino

- Formação e Relações com a Comunidade, no âmbito da Extensão

- Educação Ambiental

- Educação e Inclusão Social

- Perspectivas Teóricas - Novos Paradigmas na Educação Superior

Considerando que as produções da ANPED tratam de subtemas afins, relacionados ao tema central, mas não fazem nenhuma referência ao mesmo diretamente, optei por analisar de forma mais detalhada as produções da CAPES e da GUNI.

No conjunto de produções analisadas, constato que há uma tendência ainda bastante expressiva de dar visibilidade a como as instituições de ensino, através de suas práticas de 
ensino e/ou extensão, estão contribuindo seja para a formação dos acadêmicos na dimensão social, cidadã e/ou comunitária ou para o desenvolvimento das comunidades onde realizam programas e projetos.

Em relação à gestão, encontrei um vasto campo de abordagens e perspectivas, porém poucas produções ocupadas de explorar modelos de gestão integradores. Considerando a abordagem sistêmico-complexa da responsabilidade social e da sustentabilidade na educação superior e a perspectiva de modelos integradores das dimensões de princípios, processos e impactos no âmbito dos quatro grandes sistemas das IES (ensino-pesquisa-extensao e gestão), destaco as produções que, de alguma forma, aproximam-se mais dessa abordagem.

Entre as produções no site da GUNI, Roorda (2011), desenvolve instrumentos de educação, integrando o desenvolvimento sustentável à formação de competências e programas curriculares nas universidades; Jansen (2010), aborda que a integração entre desenvolvimento sustentável e a educação superior requer que seja repensado o sistema educativo inteiro, incluindo seus valores e normas; Noguera (2010), apresenta uma análise sobre a responsabilidade social universitária relacionada a valores e empatia; Filho (2010) explica por que a sustentabilidade na educação superior deve ser percebida como um trabalho em evolução e apresenta oportunidades e desafios para sua introdução nas universidades e Canadell (2010) enfoca a necessidade de mudar a visão fragmentada da realidade para avançar na sustentabilidade e como a educação superior pode contribuir neste processo.

Nas produções da CAPES sobre o tema, Rosseto (2009), estuda a governança corporativa como uma forma de gestão que proporciona aos shareholders estakeholders da empresa uma maior transparência, eqüidade de tratamento, prestação de contas e responsabilidade social, identificando que o ramo da educação também está despertando para essa necessidade de aderir às boas práticas de governança; Cordeiro(2009) versa sobre responsabilidade social das instituições de ensino superior na contemporaneidade, mediante um estudo de caso sobre a Gerência de Responsabilidade implantada na FTC - Salvador, salientado o despertar da consciência organizacional sobre sua co-responsbilidade ética para com a ordem social, que se expressa mediante o dever moral de executar ações que fomente a promoção e transformação social pautada na cidadania, cultura de paz e sustentabilidade; Pinto (2009), avalia como os gestores de uma universidade comunitária do Rio Grande do Sul percebem se constituir as atividades que denotam preocupação em desenvolver uma educação socialmente responsável no século XXI, entendendo que a universidade é o lócus que articula ensino, pesquisa e extensão e não pode se furtar de contribuir para o desenvolvimento sustentável da sociedade, nem deixar de divulgar as ações e os projetos que desenvolve com 
esse fim, especialmente aquelas universidades de caráter comunitário, encontrando um equilíbrio entre as ações direcionadas a seu público interno - professores, funcionários, alunos - e aquelas direcionadas ao público externo - comunidade, sociedade, parceiros, meio ambiente e governo; Oliveira(2009) apresenta uma proposta de diretrizes e ações para a promoção da universidade ambientalmente sustentável, abordando as questões referentes à estrutura organizacional, ao planejamento institucional, gestão operacional e formação para a sustentabilidade. Experiências de diversas instituições de ensino superior do Brasil e do mundo são apresentadas e discutidas pelo autor, a fim de indicar caminhos para a incorporação do desenvolvimento sustentável nas atividades de ensino, pesquisa, extensão e na própria gestão universitária e Alves (2009)perscruta onde se encontra a Universidade Federal de Uberlândia frente às questões voltadas para a sustentabilidade, para fomentar um Indicador do Eco-Conhecimento que interprete a percepção da comunidade acadêmica relacionada a essa temática, contatando a falta de estudo e aprofundamento das temáticas voltadas para o Desenvolvimento Sustentável dentro da universidade e conseqüente conhecimento difuso e incipiente dos graduandos sobre o assunto. Assim, identifica o autor que as dificuldades referentes à implementação e fomentação do Desenvolvimento Sustentável, nas esferas de produção de conhecimento científico, vão além das problemáticas vinculadas a fragmentação do conhecimento e da necessidade de uma visão global vinculados aos diferentes níveis de realidade ideológica. Para o mesmo, o problema encontra-se na não abordagem dessa temática frente todos os cursos que compõem a esfera acadêmica.

A análise das produções acima, encontradas na GUNI e na CAPES, revela que, se por um lado encontramos trabalhos que reforçam uma tendência de reduzir a responsabilidade social e a sustentabilidade nas IES na perspectiva de projetos socioambientais na área de extensão comunitária ou no enfoque fragmentado da inserção de algumas iniciativas nos currículos de alguns cursos, existem outros que estão buscando avançar na perspectiva da pesquisa e da produção de conhecimento que ofereça subsídios para construção modelos de gestão integradores que abarquem a complexidade dessas abordagens e tenham condições para impactar de forma mais significativa na mudança cultural que exigem.

A praticamente inexistência de produções específicas sobre o tema na ANPED provoca indagações. Por um lado, através dos subtemas como educação ambiental, educação inclusiva e diversidade e em alguns artigos sobre política e gestão institucional, estão sendo abordadas questões relacionadas à educação para o desenvolvimento sustentável, responsabilidade social e sustentabilidade. Porém, estas em geral estão mais voltadas para o ensino fundamental e médio em espaços públicos estatais e em sua maioria enfocam 
parcialmente algumas demandas, mas não trabalham com as perspectivas integradoras dos processos e sistemas institucionais, que a complexidade dos temas requer. Fica a questão acerca dos motivos que ajudem na compreensão desse "estado da arte" na ANPED.

\section{CONSIDERAÇÕES FINAIS}

A apresentação e a introdução da V Conferência Internacional de Barcelona sobre o Ensino Superior, promovida pelo GUNI em novembro de 2010 sob o título "Compromisso do Ensino Superior para a Sustentabilidade: do Entendimento para a Ação"6 constitui-se num importante referência para acompanhar o estado de conhecimento sobre o tema deste artigo. A sustentabilidade é tratada como um novo paradigma que requer novas formas de relacionamento responsável com a vida, consigo mesmo e com os ecossistemas e uma nova cultura, baseada na integração e na equidade.

$\mathrm{Na}$ tensão entre as necessidades de mudança, a dificuldade de imaginar uma visão de mundo capaz de dar conta dessa mudança e os instrumentos e ferramentas para sua implementação, inserem-se um conjunto de iniciativas que buscam responder a uma nova perspectiva da educação superior, seus propósitos, seus conteúdos e métodos curriculares e de pesquisa, seus sistemas organizacionais e estruturais e seu diálogo e interação com a sociedade.

Entretanto, a própria introdução da Conferência aponta que a sustentabilidade precisa ser incorporada nos processos de ensinar-aprender em todos os projetos educacionais globais, o que implica desafios como a integração das fragmentadas áreas do conhecimento numa perspectiva holística, a conexão entre pensamento e ação e a aprendizagem para trabalhar de forma transversal.

Se a grande mudança na educação superior é colocar o conhecimento a serviço da transformação social (SEGRERA, 2010), é preciso incorporar o novo nos processos de gestão e nos processos de ensinar-aprender e avançar de uma apreensão reducionista e instrumental que dá visibilidade somente aos impactos ou a melhorias de desempenho social e ambiental. É importante aprofundar a compreensão crítica sobre a potência que a responsabilidade social, a sustentabilidade e a educação para o desenvolvimento sustentável possuem, ou não, para promover uma mudança de mentalidades em direção a uma nova cultura e um novo

\footnotetext{
6 Disponível em: http://www.guni-rmies.net/conference2010/page.php?lang=2\&id=1 e http://www.gunirmies.net/conference2010/page.php?lang=2\&id=32. Acesso em 12 jun de 2011.
} 
paradigma de desenvolvimento. A pesquisa e a formação docente e de gestores nas IES são lugares de inquietação nesse processo e que desafiam a novas descobertas.

\section{REFERENCIAS}

ALVES, Charmenie Santana. Indicador do eco-conhecimento: desenvolvimento sustentável sob a ótica acadêmica. Resumo. Disponível emhttp://capesdw.capes.gov.br/ capesdw /resumo.html?idtese=20091332006012010P, acesso em 21/05/20111.

ANPED, Reunião Anual da ANPED, 2010. Disponível em http:// www. anped.org.br /reuniões/33 encontro/internas/ver/trabalhos, acesso em 20 de abril de 2011.

. Reunião Anual da ANPED, 2009. Disponível em http:// www. anped.org.br /reuniões/32ra/índex.html acesso em 20 de abril de maio de 2011.

. Reunião Anual da ANPED, 2008. Disponível em http:// www. anped.org.br /reuniões/31ra/inicio.htm, acesso em 20 de abril de 2011.

BRASIL. Lei $n .{ }^{\circ} 10.861$, de 14 de abril de 2004. Institui o Sistema Nacional de Avaliação da Educação Superior - SINAES. Presidência da República. Brasília, 2004.

BERTRAND, Ives. Teorias contemporâneas da educação. 2. ed. Lisboa : Instituto Piaget, 2001.

CAPES, Banco de Teses e Dissertações. Disponível em http://www.capes.gov.br/servicos/banco-de-teses.

CALDERÓN, Adolfo Ignácio. Responsabilidade social universitária: contribuições para o fortalecimento do debate no Brasil. Revista da Associação Brasileira das Mantenedoras de Ensino Superior. Brasília, ano 24, n 36, jun. 2006.

CANADELL, Àngels. Sostenibilidad: Una visión integradora. Disponível em: http://www.guni-rmies.net/news/detail.php?id=1596, acesso em 28/5/2011

CORDEIRO, Tiago Sá Teles. Responsabilidade Social de Instituição de Ensino Superior: O caso da FTC - Salvador. Resumo. Disponível emhttp://capesdw.capes.gov.br/ capesdw/resumo.html?idtese=20092928011015003P0, acesso em 21/05/20111.

DECLARAÇÃO DO CONGRESSO INTERNACIONAL DE REITORES LATINOAMERICANOS E CARIBENHOS - O Compromisso social das Universidades da América latina e Caribe. UFMG, Belo Horizonte, Brasil 16 a 19 setembro 2007.

FILHO. Walter Leal. La sostenibilidad en las universidades: oportunidades, desafíos y tendências. Disponível em: http://www.guni-rmies.net/news/detail.php?id=1594, acesso em $28 / 5 / 2011$

GOERGEN, Pedro. Educação superior entre formação e performance. Revista da Avaliação da Educação Superior. Campinas, vol.13, no.3, 2008 
GUNI. Global University Network for Innovation. Disponível em http://www.gunirmies.net/info/default.php?id=1/ ehttp://www.guni-rmies.net/news/default.php?sec=89

JANSEN, Leo. La contribución de la educación superior al desarrollo sostenible: el camino a seguir. Disponível em http://www.guni-rmies.net/news/detail.php?id=1612, acesso em $28 / 5 / 2011$.

MORAES, Maria Cândida. Pesquisando a partir do pensamento complexo : elementos para uma metodologia de desenvolvimento eco-sistêmico [documento impresso e eletrônico]. Educação (Porto Alegre), Porto Alegre, v.29, n.58, p. 145-172, 2006

MORIN, Edgar. Terra-pátria. Porto Alegre: Sulina, 2005.

Os sete saberes necessários à educação do futuro. 8.ed. São Paulo: Cortez, 2003.

MOROSINI, Marília Costa. Qualidade na Educação Superior: tendências do século. Estudos em Avaliação Educacional, SP, v 20, n 43, p. 1653-186, mai/ago 2009

Educação Superior em tempo de Supercomplexidade In: AUDY, Jorge Luis Nicolas; MOROSINI, Marília Costa. Inovação e empreendedorismo na universidade. Porto Alegre: EDIPUCRS, 2008. p. 78-110.

NOGUERA, Juanjo Martí. La Responsabilidad social universitaria: propuestas de desarrollos metodológicos. http://www.guni-rmies.net/news/detail.php?id=1577 em 28/5/2011.

OLIVEIRA, Mara de, DALLA ROSA, Magda, SILVA, Inês A. Um olhar sobre a responsabilidade social nas IES comunitárias. In NUNES, Ana K (org) Universidade Comunitária e Avaliação: os quinze anos do PAIUNG. Santa Cruz do Sul: UNISC, 2009.

OLIVEIRA, Márcio de. Universidade e Sustentabilidade: proposta de diretrizes e ações para uma Universidade Sustentável. Resumo. Disponível em http://capesdw .capes. gov.br /capesdw/resumo.html?idtese $=2009232005016012$ P4, acesso em 21/05/20111.

PEREIRA, M. V. Apresentação - Sociedade, Trabalho e Motivação na Vida Contemporânea. In SANTOS, Bettina S. e CARREÑO, Ángel Boza (orgs). A Motivação em Diferentes Cenários. EDIPUCRS, Porto Alegre, 2010.

PINTO, Maira Meira. Responsabilidade social em universidade comunitária: novos rumos para a educação superior. Disponível em http://capesdw.capes.gov.br /capesdw/resumo.html?idtese $=20093142005019001$ P0, acesso em 21/05/20111.

PORTAL, L.L.F. Apresentação - Sentido da Vida: essência do processo motivacional nos mais diferentes cenários. In SANTOS, Bettina S. e CARREÑO, Ángel Boza (orgs). A Motivação em Diferentes Cenários. EDIPUCRS, Porto Alegre, 2010.

ROORDA Niko. A Roadmap to SISD: System Integration of Sustainable Development in Higher Education. Disponivel emhttp://www.guni- rmies.net/ news/ detail. php ?id=1709, acesso em 28/05/2011.

ROSSETTO, Ana Cláudia. Governança corporativa em instituições de ensino superior particular: um estudo das instituições que abriram seu capital na Bovespa e aderiram às boas 
práticas de governança corporativa. Disponível em http://capesdw. capes.gov.br /capesdw/resumo.html?idtese $=2009133005010018$ P9, acesso em 21/05/20111.

SACHS, I. Caminhos para o Desenvolvimento Sustentável. Série Idéias Sustentáveis. 3 ed. Rio de janeiro: Garamond, 2008.

SANTOS, Boaventura de Sousa. Renovar a teoria crítica e reinventar a emancipação social. Tradução Mouzar Benedito. São Paulo: Boitempo,2007.

SEGRERA, Francisco L. Visión de La II Conferencia Mundial de Educación Superior (CMES,2009). Maringá, v. 32, n.1, p. 105-109, 2010.

UNESCO. Década das Nações Unidas da Educação para o Desenvolvimento Sustentável, 2005-2014: documento final. Brasília: UNESCO,OREALC, 2005.

VEIGA, J.E. da. Desenvolvimento Sustentável - o desafio do século XXI. Rio de Janeiro: Garamond, 2008, 3 ed.

VALLAEYS, François. O que significa responsabilidade social universitária? Revista Estudos da Associação Brasileira de Mantenedoras de Ensino Superior, Brasília: Associação Brasileira das Mantenedoras de Ensino Superior, ano 24, n 36, jun 2006, 27-34

ZAFFARONI, Cecília. Universidad con responsabilidad sustentable. In: Reunión AUSJAL, 2007. Anais. Disponível em http://guni-rmies.net/k2008/pagephp?lang=2\&id=32. Acesso em 4 de maio de 2010.

RECEBIBO EM: 08/09/2013

APROVADO PARA PUBLICAÇÃO EM: 14/09/2015 